\title{
Approaches to Improve Chemically Defined Synthetic Peptide Vaccines
}

\author{
Brett J. Hos ${ }^{1}$, Elena Tondini ${ }^{1}$, Sander I. van Kasteren ${ }^{2}$ and Ferry Ossendorp ${ }^{1 *}$ \\ ${ }^{1}$ Department of Immunohematology and Blood Transfusion, Leiden University Medical Center, Leiden, Netherlands, \\ ${ }^{2}$ Leiden Institute of Chemistry, The Institute for Chemical Immunology, Leiden University, Leiden, Netherlands
}

OPEN ACCESS

Edited by:

Piergiuseppe De Berardinis,

Istituto di Biochimica

delle Proteine (CNR), Italy

Reviewed by:

Peter Cresswell,

Yale School of Medicine, Yale University, United States

Else Marit Inderberg,

Oslo University Hospital,

Norway

*Correspondence:

Ferry Ossendorp

f.a.ossendorp@/umc.nl

Specialty section:

This article was submitted to

Molecular Innate Immunity,

a section of the journal

Frontiers in Immunology

Received: 23 February 2018 Accepted: 10 April 2018

Published: 26 April 2018

Citation:

Hos BJ, Tondini E, van Kasteren SI and Ossendorp F (2018)

Approaches to Improve

Chemically Defined Synthetic

Peptide Vaccines.

Front. Immunol. 9:884.

doi: 10.3389/fimmu.2018.00884
Progress made in peptide-based vaccinations to induce T-cell-dependent immune responses against cancer has invigorated the search for optimal vaccine modalities. Design of new vaccine strategies intrinsically depends on the knowledge of antigen handling and optimal epitope presentation in both major histocompatibility complex class I and -|| molecules by professional antigen-presenting cells to induce robust CD8 and CD4 T-cell responses. Although there is a steady increase in the understanding of the underlying mechanisms that bridges innate and adaptive immunology, many questions remain to be answered. Moreover, we are in the early stage of exploiting this knowledge to clinical advantage. Several adaptations of peptide-based vaccines like peptideadjuvant conjugates have been explored and showed beneficial outcomes in preclinical models; but in the clinical trials conducted so far, mixed results were obtained. A major limiting factor to unravel antigen handling mechanistically is the lack of tools to efficiently track peptide vaccines at the molecular and (sub)cellular level. In this mini-review, we will discuss options to develop molecular tools for improving, as well as studying, peptide-based vaccines.

Keywords: peptide vaccination, click chemistry, antigen presentation, intracellular processing, targeted vaccination, tumor immunology, toll-like receptors, bioorthogonal

\section{INTRODUCTION}

Recent breakthroughs in immunotherapy of cancer have unveiled that clinical responses correlate with activation and expansion of tumor-specific $\mathrm{T}$ lymphocytes that mostly target mutation-based neo-antigens (1-6). Alongside, induction of tumor-specific T-cell responses has been achieved with well-defined peptide-based vaccines in preclinical and clinical settings $(7-10)$. This indicates that therapeutic vaccination with well-defined synthetically produced neo-antigenic peptides is a viable strategy.

Immunogenicity of synthetic peptide-based vaccines can be significantly influenced by the mode of delivery (11-17). For example, efficiency of cytotoxic T-cell activation and anti-tumor immune responses is improved when peptides are encapsulated in liposomes or covalently conjugated to adjuvants $(18,19)$. Such modifications will allow optimal uptake of antigenic peptides from the vaccination site by specialized antigen-presenting cells (APCs) with efficient proteolytic processing for major histocompatibility complex (MHC) class I and class II presentation to CD8+ cytotoxicor CD4+ helper-T cells, respectively (20). However, the development of optimal peptide delivery modalities is non-trivial and largely remains a process of trial-and-error based on time-intensive and indirect read-out systems. Most of what is known about in vivo processing routes of peptides is based on murine models and little data are available in humans. Additionally, the sequence and amino acid composition may alter the physical properties and immunological behavior of individual peptides. Therefore, mechanisms of intracellular routing and processing of administered peptides in APC require in depth examination. 
The processing machineries for peptide loading in MHC class I or -II for presentation is characterized by distinct protease systems. While MHC class I processing pathways involves cytosolic proteasomes, peptidases and ER-resident trimming aminopeptidases, MHC class II peptide production takes place in endolysomal compartments involving cathepsin-like proteases $(21,22)$. The cell biology of antigen presentation and cross-presentation, a specialized mechanism to process exogenous engulfed protein antigen for MHC class I, by dendritic cells (DCs) is not fully elucidated in detail but is crucial knowledge for optimal vaccine design $(20,22)$. Improving our knowledge on vaccine behavior is therefore essential for rationally designing peptide-based vaccines. However, tracking of vaccine components through the developing stages of an immune response remains difficult with present day techniques. Bulky labeling groups that are used to visualize peptides affect their physiochemical properties, which likely alters the way a peptide is internalized, processed, and presented. It is therefore vital to apply detection strategies that minimally impact the processing of peptides.

This mini-review encompasses our current knowledge of peptide-based vaccine modalities, the possibilities to properly target them through defined alterations, novel options for rational design, and the development of (bio)chemical visualization tools to improve our understanding of peptide-based vaccine behavior in vivo.

\section{PEPTIDE VACCINATION HISTORY}

Peptide vaccination is based on the biological concept that induction of a T-cell response relies on the specificity of the T-cell receptor to recognize a presented oligopeptide-epitope. This epitope corresponds to only a fraction of the entire protein (polypeptide) antigen. Therefore, to initiate a T-cell response against a specific protein, a vaccine essentially needs to include only the minimal immunogenic peptide sequence which can be produced synthetically.

Vaccination with minimal epitopes in form of synthetic peptides was shown to raise antigen-specific T-cell responses (23) and represented an exciting step forward in modern vaccination biology. Immunogenicity studies in preclinical models showed effective induction of T-cell responses and the potential for its application in cancer immunotherapy was recognized. However, clinical translation of this concept did not lead to the results anticipated by the first studies (24-29). As an example, vaccination with the immunogenic peptide of the differentiation antigen gp 100 for the treatment of melanoma, failed to elicit sufficiently effective $\mathrm{T}$-cell responses in several clinical trials, even when relatively high numbers of antigen-specific cells were detected (30-32).

Comprehensive in vivo studies have revealed that, rather than the exact epitope, peptides consisting of a termini-extended sequence (long peptides) promotes higher quality T-cell responses (33). In fact, exact epitopes can directly bind on MHC class I molecules present on the surface of any somatic cell, most of which are non-professional APCs, which causes suboptimal T-cell priming. On the other hand, long peptides are processingdependent and can be presented only by professional APC, which are specialized and equipped for engulfing, processing, and presenting the antigenic peptides coinciding with optimal T-cell co-stimulation $(34,35)$.

The first peptide vaccination studies in humans were carried out with long peptides derived from self-antigens mucin and HER-2/neu, and mutated K-RAS. These studies reported safety of synthetic peptide administration and an observation of tumor- or antigen-specific T-cell responses (36-39). These clinical studies provided the basis for the use of long peptides as a strategy to design more efficacious vaccines for cancer treatment. In a study conducted in an HPV-induced preclinical model, vaccination with a 35 amino acid long synthetic peptide covering a CTL and a T helper epitope of the HPV16 E7 protein, improved T-cell responses compared with vaccination with minimal epitopes and controlled tumor growth (40). The use of long peptides bolstered priming by professional APCs that resulted in higher T-cell expansion, memory formation, and markedly improved efficacy. This paved the way for clinical testing of a mixture of overlapping peptides of 32-35 amino acids covering the sequence of the E6 and E7 HPV16 proteins for the treatment of HPV-associated gynecological tumors $(10,41)$.

Synthetic peptide vaccination also holds high potential for the novel field of cancer vaccination against mutation-derived neoantigens. The ambition of raising an immune response against tumor-specific mutated proteins by vaccination represents an exciting challenge that has animated cancer therapeutic research over the last few years. Efforts needed in determining the MHCrestricted epitopes may be bypassed by designing a peptide that spans the amino acid sequence on either side of the mutation. Interestingly, this concept has been successfully applied in a recent phase I study on melanoma patients (9). In this study, six patients were vaccinated with 13-20 different peptides of 15-30 amino acids designed to target an equal amount of patientspecific somatic mutations of the sequenced tumor. All patients exhibited enhanced neo-antigen-specific T-cell populations after peptide vaccination and displayed objective clinical responses, even though two patients required a supplemental treatment with anti-PD1 immuno-modulatory antibody to reach complete tumor regression. In perspective, the use of multiple long peptides for vaccination may be complicated, as the behavior of different amino acids sequences, in terms of physico-chemical properties, solubility, and bio-distribution may differ.

Concurrently, a similar approach has been developed by encoding selected patient-specific epitopes in RNA molecules (8), as the window of physico-chemical properties is smaller for these oligomers than for peptides. Also this RNA-based vaccination was able to induce a personalized tumor-specific T-cell response with clinical benefits. Both studies represent an important proof of concept for the field of neo-antigen vaccination and stimulate research to progress toward the most effective vaccination approach.

\section{SYNTHETIC PEPTIDES: VERSATILE VACCINE ANTIGENS}

One advantage in the use of synthetic peptides as vaccines from both an immunological and a chemical point of view is their 
versatility. Immunologically, peptide vaccines induce better T-cell responses compared with full protein vaccines $(42,43)$. In fact, peptides are more efficiently endocytosed, processed, and presented on MHC molecules compared with full proteins. Other, less understood, aspects of antigen handling by APC, indicate that antigen cross-presentation-on a mole-for-mole ratio-is more optimal for peptides than protein. This is perhaps due to efficient translocation of peptides into the cytoplasm from endosomes (44).

On the other hand, peptides are chemically easier to produce than protein antigens as they do not necessitate folding into a tertiary structure. The high throughput and parallel production set-ups for synthetic peptides allows that several variations in the linear sequence can be made to refine vaccine formulation. Collateral problems such as induction of tolerance or suboptimal priming $(45,46)$ can potentially be circumvented by conjugation to "adjuvant" molecules that allow targeting of APCs and contribute to adequate immune-stimulation.

A feasible strategy to improve APC targeting of synthetic peptides and at the same time deliver the right signals is to integrate ligands of pattern-recognition receptors (PRRs), such as C-type lectin- (CLR), toll-like- (TLR), and NOD-like-receptors. These receptors are highly expressed by professional APCs and are essential for pathogen sensing and immune-stimulation. Different ligands have been identified for these receptors which can be employed for targeting and immune-stimulation. This approach can also modulate the internalization routing of endocytosed antigen (47). For example, the CLR-specific mannosylation of long peptides canalized intracellular trafficking toward early endosomal low-degradative compartments rather than lysosomes for degradation, compared with non-mannosylated peptide. This, favored antigen presentation and enhanced T-cell activation both in vitro and in vivo (15).

A second approach that has resulted in improved T-cell activation has been the direct conjugation of long peptides to TLR ligands. TLR-mediated trafficking was described to impact antigen presentation. A study shows that the presence of antigen and TLR ligand in the same endosomes determines entrance to the presentation pathways, suggesting that TLRs or other PRRs might have an important role in determining efficient presentation after antigen uptake (48). Conjugation of antigenic peptides to TLR ligands like the TLR9-ligand CpG or the TLR1/2 heterodimer agonist $\mathrm{Pam}_{3} \mathrm{CSK}_{4}$ have been shown to strongly improve T-cell priming in vivo thanks to the combined effect of increased uptake of long peptides and co-delivery with the immune-stimulatory signal $(49,50)$. Furthermore, the $\mathrm{Pam}_{3} \mathrm{CSK}_{4}$-conjugates were able to establish potent anti-tumor immune responses in multiple preclinical models and are now being tested in a phase I/II clinical trial evaluating synthetic peptide vaccination for treatment of HPV-induced cancers $(19,50)$ (ClinicalTrials.gov Identifier: NCT02821494). This represents a promising platform for potentiating neo-epitope-based personalized peptide vaccines.

A third targeting strategy includes the conjugation of peptide to a DC-targeting antibody, as reported in a study evaluating the DC-specific receptor DEC205 antibody (51). Targeting viralspecific long peptides to DEC205 promotes peptide uptake by DEC205+ cells and leads to enhanced presentation on MHC class I, which resulted in improved protection to viral challenge. Interestingly, no effect was observed in the efficiency of $\mathrm{MHC}$ class II presentation. This highlights the fact that peptide targeting does not only influence which cells will engulf the antigen, but also impacts intracellular trafficking and fate of the antigen for presentation on either MHC class I or II. This becomes more evident in a comparative study on antibody-mediated targeting to either mannose receptor, DEC205, or CD40 in human DCs (52). Targeting of different receptors leads to differential uptake efficiency and endosomal antigen localization. While targeting of the co-stimulatory molecule CD40 was associated to the lowest uptake, it was also associated to the most efficient MHC class II and cross-presentation. In this setting, DEC205-targeting was associated to routing to degradative compartments and lowMHC class I presentation, which could be rescued by inhibiting degradation. These observations expose the complex relations between APC subsets, endosomal routing, and antigen presentation efficiency.

Lastly, an efficient approach is the encapsulation of long peptides in structures such as nanoparticles, liposomes, or nano/ hydrogel-systems to enhance T-cell priming by DCs (53-56). Particulate vaccines have been shown to be well internalized by various professional APCs. Properties of these particles, e.g., charge, size, composition, can be modulated to influence uptake by different cells, and vaccine dispersion after injection (57). In the case of liposomes, smaller particles are better internalized by DCs than larger, and positively charged cationic liposomes increase ROS production and cross-presentation $(58,59)$. The added benefit of nano/hydrogels is the possible incorporation of environmental ques which are slowly released during the induction of DC maturation while peptide can be processed and presented (14). A shared advantage of these delivery systems is the ability to prevent the rapid release of high quantities of free peptide.

\section{MODULATING THE VACCINE RESPONSE}

Recent reports has highlighted that initiation of an adaptive immune response is more than an APC meeting a T cell. Complex interactions of several APC subsets and their crosstalk with other cell types within the vaccination-draining lymph node will determine the outcome of the immune reaction (60-63). Additionally, different APCs can induce different types of immune reactions due to their intrinsic characteristics (61-63). By the application of alternative formulations or conjugations with PRR ligands of peptides-based vaccines, modulation of the immune reaction may be possible by delivering the antigen toward the proper APC to initiate the proper immune response. To optimally design peptide-based vaccines in the future; it is thus necessary to understand the consequences of modifications in APC targeting.

Recently, the importance of cross-presenting DCs in the initiation of an effective anti-tumor immune response was exemplified in several studies (64-66). Tissue originating cross-presenting DCs were shown to be required to migrate from the tumor microenvironment (TME), loaded with antigens from the tumor, toward the draining lymph node, to induce CD8 T cell-dependent delay of tumor outgrowth. This special DC type was characterized by the expression of CD103 and is a DC subtype closely related 
to the cross-presenting CD8 $\alpha$-expressing DCs that reside in the secondary lymphoid organs (67). These DC subtypes are indicated as part of the type 1 conventional DC (cDC1) group, have a common expression of the previously mentioned C-type lectin receptor DEC205 that was exploited successfully for improved cross-presentation, as well as the "dead cell-receptor" CLEC9A, and has an homolog in the human DC family (68-70). Closely related is the macrophage lineage originating Langerhans cell, which shows similar cross-priming capabilities as $\mathrm{CDC} 1 \mathrm{~s}$ and is a shared population between mice and humans. Their characteristic expression of c-type lectin receptor Langerin-1 has been used in antibody-mediated targeting to improve cross-presentation and CTL activation (17).

Additionally, the induction of effective CD4 helper responses are crucial for improved CD8 T-cell priming and memory formation, increased tumor infiltration, and local effectiveness (58-60). The DC family has, likewise the conventional DC type 1, a type 2 conventional DC with the characteristic expression of CD11b, which is considered specialized in their capacity to induce T-cell help while lacking CD8 priming capacity (67). However, exploration of specific targeting of this DC subtype for improved helper T-cell priming had negligible attention, due to the intrinsic capacity of most DCs to present in MHC class II. Therefore, it appears more effective to incorporate vaccine modalities which harbor both CD4 and CD8 epitopes and target a wide range of DC subsets, including cross-presenting DCs.

Furthermore, potent peptide-based vaccines can modulate the TME as shown by shifts in the myeloid subpopulations in the tumor $(19,71)$. Most likely, polarization of CD4 T-cell subsets will regulate the TME to a more proinflammatory state. This is supported by TLR2 ligand-conjugated HPV long peptides which can strongly activate CD4 and CD8 T cells from tumor-draining lymph nodes of cervical cancer patients (50). Other options to modulate the suppressive TME can be achieved by combining cancer vaccines with classical chemotherapy (72) or widely used checkpoint blocking antibodies like anti-PD-1 or anti-PD-L1 (65, 73-78).

The application of TLR-ligand $\mathrm{Pam}_{3} \mathrm{CSK}_{4}$ as targeting moiety was highly promising due to a broad expression of its receptor in dermal DCs $(79,80)$. The added benefit of a TLR ligand is the combination of a maturation signal with an antigen. Maturation of the DC is known to strongly influence the intracellular machinery and processing of exogenous antigens (81-83). By conjugation of a maturation signal with the antigen, the survival of internalized antigen is increased by the formation of antigen storage depots for prolonged presentation and priming (84). The application of ligands for other PRRs is of interest as well (85). However, care should be taken in using combinations of different PRR ligands in the same modality. Different PRR pathways may affect each other upon simultaneous activation and reduce DC proinflammatory responses, which is exploited by some pathogens $(86,87)$.

In conclusion, these findings shows that the field is steadily progressing to unravel the relevant cell types involved in optimal (cross-)presentation of antigens. Peptide-based vaccination studies using antigen-bound fluorophores show co-localization with endosomal markers in DC, which correlated with a robust antigen-specific T-cell immune response. However, the strong influence of the relatively large fluorophore on the physicochemical properties of the antigenic peptide to gain trustworthy physiological information and the limitations to detect peptide intermediates makes interpretations of this complex process difficult. To unravel how activation of APCs orchestrate molecular and cellular mechanisms of antigen processing and presentation operate in vivo, and how we can incorporate this knowledge in peptide-based vaccination modalities requires better tracking and visualization tools of vaccine moieties.

\section{NOVEL CHEMICAL VISUALIZATION TOOLS}

Several technologies to visualize antigens in APCs, other than using T-cell readouts, have been developed in the last decades. Most of these have relied on tracking the activity of an enzyme through a cell. Examples of enzymes used for this are $\beta$-lactamase, luciferase, and horseradish peroxidase. Using these approaches, the endocytic compartments involved in (cross-)presentation could be observed, as well as the cytosolic location of proteins during this event (88-90). Fluorophore-labeled antigens have also been used to study the intracellular movement of antigen in an APC. Using this approach, the presence of intracellular antigen depots was, for example, identified (84).

However, these approaches also have their constraints. For reporter proteins, the main constraint is that degradation is the hallmark of antigen (cross-)presentation: during antigen presentation any protein must be degraded into peptides to allow for its MHC-loading. As enzyme activities are reliant on largely intact proteins, this means that later stages of the pathway will be invisible using this approach. The use of fluorophore-modified antigens partially solves this by making the detectable signal independent of the intactness of the protein. However, the physicochemical properties of fluorophores must also be considered. Due to their bulky and hydrophobic structure compared with relatively small peptides, fluorophores could strongly influence the behavior of the antigenic peptide and mask epitope residues as well as proteolytic cleavage sites. Moreover, the size of conjugated fluorophores may hamper these peptides to pass through the proteasomal $\alpha$-annulus of several ångström wide (91). Similarly, peptide translocation by TAP (transporter associated with antigen presentation) to the ER lumen for presentation in MHC class I molecules may be strongly influenced (92). Furthermore, it is difficult, if not impossible, to rule out that constructs lose their fluorophores during processing. As a consequence, not much data exists of later processing stages that could directly visualize antigen. And even in rare cases in which it has been possible [e.g., the H-2K $\mathrm{K}^{\mathrm{b}}$-SIINFEKL pMHC complex antibody 25-D1.16 (93)], translation to other antigens is not obvious. Therefore, a method to thoroughly and accurately apply tracking across a manifold of peptide-based vaccine modalities and the complex cellular interactions involved is highly wanted (see Figure 1).

One field of chemistry of which we are currently exploring the potential is click chemistry (94). This type of chemistry involves a defined ligation reaction between a small bioorthogonal chemical group - a chemical group which can be selectively 

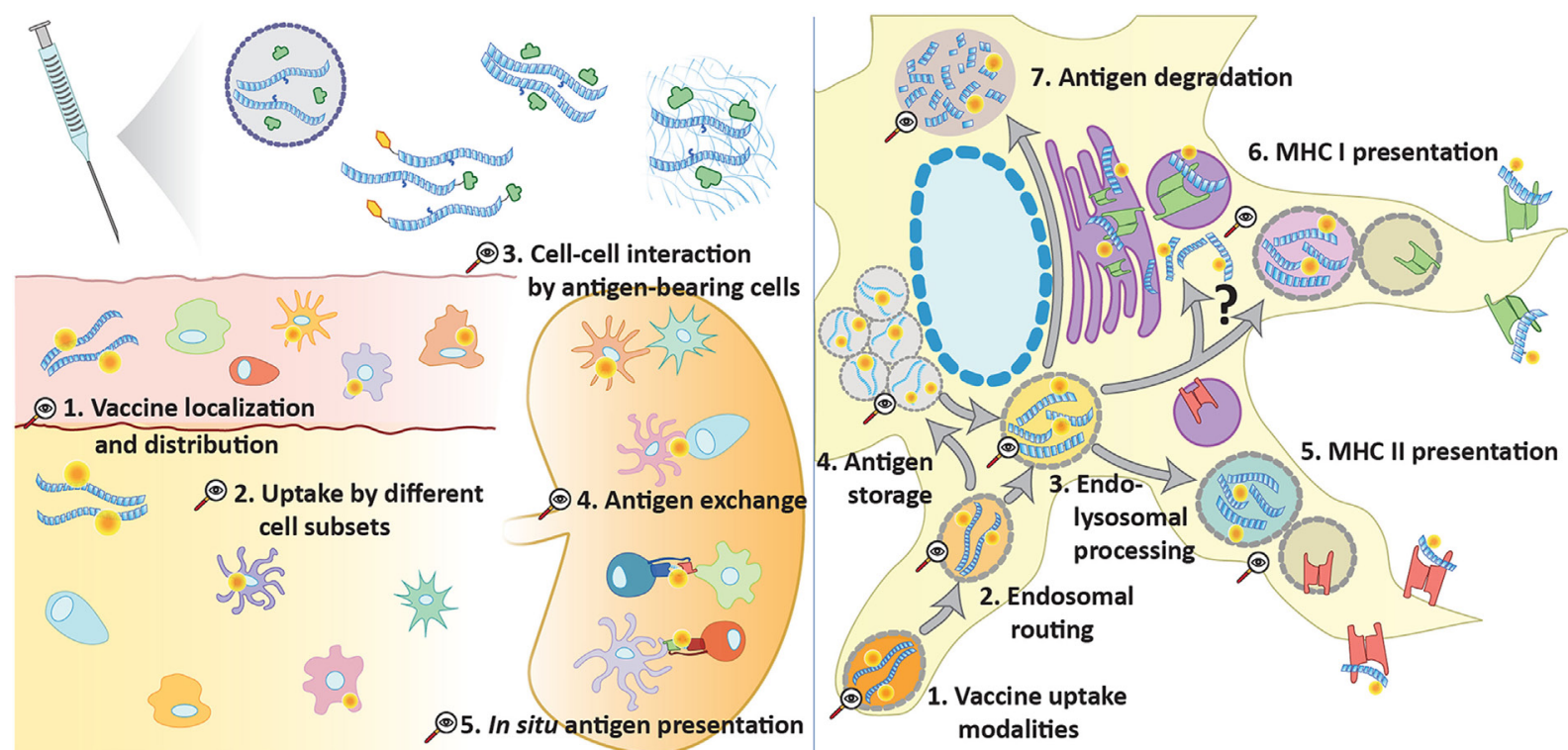

FIGURE 1 | Opportunities for advanced tracking techniques in vaccination. Several forms of peptide antigen can be traced (e.g., via click chemistry) at multiple levels to provide further understanding of vaccine processing and induction of adaptive immunity. At a supracellular level, it can unveil vaccine diffusion, drainage, and the main cellular recipients. Tracking of antigen in different cell types can also help to understand the steps involved in the initiation of an immune response, such as cell-cell interaction, antigen exchange, and in situ antigen presentation. At a subcellular level, peptide tracking is an important tool to explore the intracellular events that lead to antigen presentation following antigen uptake: endosomal trafficking and sorting to storage compartments, class I or class II presentation or degradation.

ligated within the context of the living cell or organism - to form a covalent linkage to a detectable group after the biological time course has been completed. It is relatively easy (in Escherichia coli) to produce bioorthogonally labeled recombinant proteins (95-97) using methionine auxotrophic producer strains in combination with bioorthogonal methionine analogs $(98,99)$. This chemistry has been applied widely, but its application to immunology is still in its infancy. We ourselves have applied this chemistry to label surface loaded minimal epitopes on the surface of APCs (100) to allow their quantification without using T-cell reagents. However, the reaction is still limited by poor signal-to-noise ratios that cannot compare with the sensitivity of T cells. Detection of the handles in antigens after routing and processing is therefore not yet possible using this approach, despite the groups surviving the antigen presentation pathway (101-103). Once the sensitivity issues can be solved this technique could prove valuable in the imaging of the entire antigen routing pathway with minimal bias. Additionally, this approach may be suited to analyze the in vivo fate of chemically defined peptide vaccines. By ex vivo secondary staining of relevant cell types or tissues using fluorescent microscopy or histological analysis, the presence and location of the peptide vaccine can be determined. This could be valuable information to improve peptide vaccine design.

\section{CONCLUDING REMARKS}

Our current knowledge on innate and adaptive immune system allows us to design molecularly well-defined vaccine moieties. Adjuvant molecules that bind PRR can be synthetically coupled to antigenic peptide sequences. Even though these defined peptide vaccines have strong vaccination capacity, the mechanisms underlying these improvements are only understood to a basal level. To improve the design of peptide-based vaccines, we need to better our understanding of chemically altered vaccines on the events unfolding during vaccination in vivo. A major limitation to this understanding is the lack of techniques that allow the study of late stages of antigen processing, and presentation on a cellular and molecular level. Fundamental questions about transfer of peptides within and between cells are currently troublesome since tags or fluorophores are lost and prone to altering essential physicochemical properties due to their bulkiness. The introduction of novel types of chemistry may in future circumvent these problems, which in turn may lead to novel insight in the complex cellular and molecular interactions in immune response induction.

\section{AUTHOR CONTRIBUTIONS}

$\mathrm{BH}$ and ET have contributed equally to the manuscript in writing and figure design. SK and FO have been responsible for scientific input and revisions of the final manuscript.

\section{FUNDING}

$\mathrm{BH}, \mathrm{SK}$, and FO have received funding by The Netherlands Organization for Scientific Research (NWO) through the gravitational program 2013 granted to the Institute of Chemical Immunology (ICI-024.002.009). ET is funded by the University Leiden Profiling Area Bioscience: the Science Base of Health. 


\section{REFERENCES}

1. Riaz N, Havel JJ, Makarov V, Desrichard A, Urba WJ, Sims JS, et al. Tumor and microenvironment evolution during immunotherapy with nivolumab. Cell (2017) 171(4):934-49. e15. doi:10.1016/j.cell.2017.09.028

2. Verdegaal EM, de Miranda NF, Visser M, Harryvan T, van Buuren MM, Andersen RS, et al. Neoantigen landscape dynamics during human melanomaT cell interactions. Nature (2016) 536(7614):91-5. doi:10.1038/nature18945

3. Boon T, Cerottini JC, Van den Eynde B, van der Bruggen P, Van Pel A. Tumor antigens recognized by T lymphocytes. Annu Rev Immunol (1994) 12:337-65. doi:10.1146/annurev.iy.12.040194.002005

4. Arens R, van Hall T, van der Burg SH, Ossendorp F, Melief CJ. Prospects of combinatorial synthetic peptide vaccine-based immunotherapy against cancer. Semin Immunol (2013) 25(2):182-90. doi:10.1016/j.smim.2013.04.008

5. McGranahan N, Furness AJS, Rosenthal R, Ramskov S, Lyngaa R, Saini SK, et al. Clonal neoantigens elicit $\mathrm{T}$ cell immunoreactivity and sensitivity to immune checkpoint blockade. Science (2016) 351(6280):1463-9. doi:10.1126/ science.aaf 1490

6. Snyder A, Makarov V, Merghoub T, Yuan J, Zaretsky JM, Desrichard A, et al. Genetic basis for clinical response to CTLA-4 blockade in melanoma. N Engl J Med (2014) 371(23):2189-99. doi:10.1056/NEJMoa1406498

7. Melief CJ, van der Burg SH. Immunotherapy of established (pre)malignant disease by synthetic long peptide vaccines. Nat Rev Cancer (2008) 8(5):351-60. doi: $10.1038 /$ nrc2373

8. Sahin U, Derhovanessian E, Miller M, Kloke BP, Simon P, Lower M, et al. Personalized RNA mutanome vaccines mobilize poly-specific therapeutic immunity against cancer. Nature (2017) 547(7662):222-6. doi:10.1038/ nature23003

9. Ott PA, Hu Z, Keskin DB, Shukla SA, Sun J, Bozym DJ, et al. An immunogenic personal neoantigen vaccine for patients with melanoma. Nature (2017) 547(7662):217-21. doi:10.1038/nature22991

10. Kenter GG, Welters MJ, Valentijn AR, Lowik MJ, Berends-van der Meer DM, Vloon AP, et al. Vaccination against HPV-16 oncoproteins for vulvar intraepithelial neoplasia. N Engl J Med (2009) 361(19):1838-47. doi:10.1056/ NEJMoa0810097

11. Mueller M, Schlosser E, Gander B, Groettrup M. Tumor eradication by immunotherapy with biodegradable PLGA microspheres-an alternative to incomplete Freund's adjuvant. Int J Cancer (2011) 129(2):407-16. doi:10.1002/ ijc. 25914

12. Lynn GM, Laga R, Darrah PA, Ishizuka AS, Balaci AJ, Dulcey AE, et al. In vivo characterization of the physicochemical properties of polymer-linked TLR agonists that enhance vaccine immunogenicity. Nat Biotechnol (2015) 33(11):1201-10. doi:10.1038/nbt.3371

13. Zhu G, Lynn GM, Jacobson O, Chen K, Liu Y, Zhang H, et al. Albumin/ vaccine nanocomplexes that assemble in vivo for combination cancer immunotherapy. Nat Commun (2017) 8(1):1954. doi:10.1038/s41467-017-02191-y

14. Weiden J, Tel J, Figdor CG. Synthetic immune niches for cancer immunotherapy. Nat Rev Immunol (2017) 18(3):212-9. doi:10.1038/nri.2017.89

15. Rauen J, Kreer C, Paillard A, van Duikeren S, Benckhuijsen WE, Camps MG, et al. Enhanced cross-presentation and improved CD8+ T cell responses after mannosylation of synthetic long peptides in mice. PLoS One (2014) 9(8):e103755. doi:10.1371/journal.pone.0103755

16. Berti F, Adamo R. Recent mechanistic insights on glycoconjugate vaccines and future perspectives. ACS Chem Biol (2013) 8(8):1653-63. doi:10.1021/ cb400423g

17. Fehres CM, Duinkerken S, Bruijns SC, Kalay H, van Vliet SJ, Ambrosini M, et al. Langerin-mediated internalization of a modified peptide routes antigens to early endosomes and enhances cross-presentation by human Langerhans cells. Cell Mol Immunol (2017) 14(4):360-70. doi:10.1038/cmi.2015.87

18. Varypataki EM, Benne N, Bouwstra J, Jiskoot W, Ossendorp F. Efficient eradication of established tumors in mice with cationic liposome-based synthetic long-peptide vaccines. Cancer Immunol Res (2017) 5(3):222-33. doi:10.1158/2326-6066.CIR-16-0283

19. Zom GG, Khan S, Britten CM, Sommandas V, Camps MG, Loof NM, et al. Efficient induction of antitumor immunity by synthetic toll-like receptor ligandpeptide conjugates. Cancer Immunol Res (2014) 2(8):756-64. doi:10.1158/ 2326-6066.CIR-13-0223

20. Blander JM. Regulation of the cell biology of antigen cross-presentation. Annu Rev Immunol (2018) 36. doi:10.1146/annurev-immunol-041015-055523
21. Kloetzel PM, Ossendorp F. Proteasome and peptidase function in MHCclass-I-mediated antigen presentation. Curr Opin Immunol (2004) 16(1): 76-81. doi:10.1016/j.coi.2003.11.004

22. Rock KL, Reits E, Neefjes J. Present yourself! By MHC class I and MHC class II molecules. Trends Immunol (2016) 37(11):724-37. doi:10.1016/j.it. 2016.08.010

23. Aichele P, Hengartner H, Zinkernagel RM, Schulz M. Antiviral cytotoxic $\mathrm{T}$ cell response induced by in vivo priming with a free synthetic peptide. J Exp Med (1990) 171(5):1815-20. doi:10.1084/jem.171.5.1815

24. Rosenberg SA, Yang JC, Restifo NP. Cancer immunotherapy: moving beyond current vaccines. Nat Med (2004) 10(9):909-15. doi:10.1038/nm1100

25. Mukherji B, Chakraborty NG, Yamasaki S, Okino T, Yamase H, Sporn JR, et al. Induction of antigen-specific cytolytic $\mathrm{T}$ cells in situ in human melanoma by immunization with synthetic peptide-pulsed autologous antigen presenting cells. Proc Natl Acad Sci U S A (1995) 92(17):8078-82. doi:10.1073/ pnas.92.17.8078

26. Cormier JN, Salgaller ML, Prevette T, Barracchini KC, Rivoltini L, Restifo NP, et al. Enhancement of cellular immunity in melanoma patients immunized with a peptide from MART-1/melan A. Cancer J Sci Am (1997) 3(1):37-44.

27. Nestle FO, Alijagic S, Gilliet M, Sun Y, Grabbe S, Dummer R, et al. Vaccination of melanoma patients with peptide- or tumor lysate-pulsed dendritic cells. Nat Med (1998) 4(3):328-32. doi:10.1038/nm0398-328

28. Rosenberg SA, Yang JC, Schwartzentruber DJ, Hwu P, Marincola FM, Topalian SL, et al. Immunologic and therapeutic evaluation of a synthetic peptide vaccine for the treatment of patients with metastatic melanoma. Nat Med (1998) 4(3):321-7. doi:10.1038/nm0398-321

29. Jager E, Gnjatic S, Nagata Y, Stockert E, Jager D, Karbach J, et al. Induction of primary NY-ESO-1 immunity: CD8+ T lymphocyte and antibody responses in peptide-vaccinated patients with NY-ESO-1+ cancers. Proc Natl Acad Sci U S A (2000) 97(22):12198-203. doi:10.1073/pnas.220413497

30. Sosman JA, Carrillo C, Urba WJ, Flaherty L, Atkins MB, Clark JI, et al. Three phase II cytokine working group trials of gp100 (210M) peptide plus highdose interleukin-2 in patients with HLA-A2-positive advanced melanoma. J Clin Oncol (2008) 26(14):2292-8. doi:10.1200/JCO.2007.13.3165

31. Schwartzentruber DJ, Lawson DH, Richards JM, Conry RM, Miller DM, Treisman J, et al. gp100 peptide vaccine and interleukin-2 in patients with advanced melanoma. N Engl J Med (2011) 364(22):2119-27. doi:10.1056/ NEJMoa1012863

32. Rosenberg SA, Sherry RM, Morton KE, Scharfman WJ, Yang JC, Topalian SL, et al. Tumor progression can occur despite the induction of very high levels of self/tumor antigen-specific CD8+ T cells in patients with melanoma. J Immunol (2005) 175(9):6169-76. doi:10.4049/jimmunol.175.9.6169

33. Bijker MS, van den Eeden SJ, Franken KL, Melief CJ, Offringa R, van der Burg SH. CD8+ CTL priming by exact peptide epitopes in incomplete Freund's adjuvant induces a vanishing CTL response, whereas long peptides induce sustained CTL reactivity. J Immunol (2007) 179(8):5033-40. doi:10.4049/jimmunol. 179.8.5033

34. Kast WM, Brandt RM, Melief CJ. Strict peptide length is not required for the induction of cytotoxic T lymphocyte-mediated antiviral protection by peptide vaccination. Eur J Immunol (1993) 23(5):1189-92. doi:10.1002/eji. 1830230534

35. Bijker MS, van den Eeden SJ, Franken KL, Melief CJ, van der Burg SH, Offringa R. Superior induction of anti-tumor CTL immunity by extended peptide vaccines involves prolonged, DC-focused antigen presentation. Eur J Immunol (2008) 38(4):1033-42. doi:10.1002/eji.200737995

36. Gjertsen MK, Bakka A, Breivik J, Saeterdal I, Solheim BG, Soreide O, et al. Vaccination with mutant ras peptides and induction of T-cell responsiveness in pancreatic carcinoma patients carrying the corresponding RAS mutation. Lancet (1995) 346(8987):1399-400. doi:10.1016/S0140-6736(95)92408-6

37. Goydos JS, Elder E, Whiteside TL, Finn OJ, Lotze MT. A phase I trial of a synthetic mucin peptide vaccine. Induction of specific immune reactivity in patients with adenocarcinoma. J Surg Res (1996) 63(1):298-304. doi:10.1006/ jsre.1996.0264

38. Disis ML, Grabstein KH, Sleath PR, Cheever MA. Generation of immunity to the HER-2/neu oncogenic protein in patients with breast and ovarian cancer using a peptide-based vaccine. Clin Cancer Res (1999) 5(6):1289-97.

39. Knutson KL, Schiffman K, Disis ML. Immunization with a HER-2/neu helper peptide vaccine generates HER-2/neu CD8 T-cell immunity in cancer patients. J Clin Invest (2001) 107(4):477-84. doi:10.1172/JCI11752 
40. Zwaveling S, Ferreira Mota SC, Nouta J, Johnson M, Lipford GB, Offringa R, et al. Established human papillomavirus type 16-expressing tumors are effectively eradicated following vaccination with long peptides. J Immunol (2002) 169(1):350-8. doi:10.4049/jimmunol.169.1.350

41. van Poelgeest MI, Welters MJ, van Esch EM, Stynenbosch LF, Kerpershoek G, van Persijn van Meerten EL, et al. HPV16 synthetic long peptide (HPV16SLP) vaccination therapy of patients with advanced or recurrent HPV16induced gynecological carcinoma, a phase II trial. J Transl Med (2013) 11:88. doi:10.1186/1479-5876-11-88

42. Rosalia RA, Quakkelaar ED, Redeker A, Khan S, Camps M, Drijfhout JW, et al. Dendritic cells process synthetic long peptides better than whole protein, improving antigen presentation and T-cell activation. Eur J Immunol (2013) 43(10):2554-65. doi:10.1002/eji.201343324

43. Zhang H, Hong H, Li D, Ma S, Di Y, Stoten A, et al. Comparing pooled peptides with intact protein for accessing cross-presentation pathways for protective CD8+ and CD4+ T cells. J Biol Chem (2009) 284(14):9184-91. doi:10.1074/jbc.M809456200

44. Menager J, Ebstein F, Oger R, Hulin P, Nedellec S, Duverger E, et al. Crosspresentation of synthetic long peptides by human dendritic cells: a process dependent on ERAD component p97/VCP but Not sec61 and/or Derlin-1. PLoS One (2014) 9(2):e89897. doi:10.1371/journal.pone.0089897

45. Toes RE, Offringa R, Blom RJ, Melief CJ, Kast WM. Peptide vaccination can lead to enhanced tumor growth through specific T-cell tolerance induction. Proc Natl Acad Sci U S A (1996) 93(15):7855-60. doi:10.1073/pnas.93.15.7855

46. Toes RE, Blom RJ, Offringa R, Kast WM, Melief CJ. Enhanced tumor outgrowth after peptide vaccination. Functional deletion of tumor-specific CTL induced by peptide vaccination can lead to the inability to reject tumors. J Immunol (1996) 156(10):3911-8.

47. Schuette V, Burgdorf S. The ins-and-outs of endosomal antigens for crosspresentation. Curr Opin Immunol (2014) 26:63-8. doi:10.1016/j.coi.2013.11.001

48. Blander JM, Medzhitov R. Toll-dependent selection of microbial antigens for presentation by dendritic cells. Nature (2006) 440(7085):808-12. doi:10.1038/ nature04596

49. Khan S, Bijker MS, Weterings JJ, Tanke HJ, Adema GJ, van Hall T, et al. Distinct uptake mechanisms but similar intracellular processing of two different toll-like receptor ligand-peptide conjugates in dendritic cells. J Biol Chem (2007) 282(29):21145-59. doi:10.1074/jbc.M701705200

50. Zom GG, Welters MJ, Loof NM, Goedemans R, Lougheed S, Valentijn RR, et al. TLR2 ligand-synthetic long peptide conjugates effectively stimulate tumor-draining lymph node $\mathrm{T}$ cells of cervical cancer patients. Oncotarget (2016) 7(41):67087-100. doi:10.18632/oncotarget.11512

51. Swee LK, Guimaraes CP, Sehrawat S, Spooner E, Barrasa MI, Ploegh HL. Sortase-mediated modification of alphaDEC205 affords optimization of antigen presentation and immunization against a set of viral epitopes. Proc Natl Acad Sci U S A (2013) 110(4):1428-33. doi:10.1073/pnas.1214994110

52. Chatterjee B, Smed-Sorensen A, Cohn L, Chalouni C, Vandlen R, Lee BC, et al. Internalization and endosomal degradation of receptor-bound antigens regulate the efficiency of cross presentation by human dendritic cells. Blood (2012) 120(10):2011-20. doi:10.1182/blood-2012-01-402370

53. Vartak A, Sucheck SJ. Recent advances in subunit vaccine carriers. Vaccines (Basel) (2016) 4(2):E12. doi:10.3390/vaccines4020012

54. Rahimian S, Fransen MF, Kleinovink JW, Christensen JR, Amidi M, Hennink WE, et al. Polymeric nanoparticles for co-delivery of synthetic long peptide antigen and poly IC as therapeutic cancer vaccine formulation. J Control Release (2015) 203:16-22. doi:10.1016/j.jconrel.2015.02.006

55. Varypataki EM, Silva AL, Barnier-Quer C, Collin N, Ossendorp F, Jiskoot W. Synthetic long peptide-based vaccine formulations for induction of cell mediated immunity: a comparative study of cationic liposomes and PLGA nanoparticles. J Control Release (2016) 226:98-106. doi:10.1016/j.jconrel.2016.02.018

56. Bachmann MF, Jennings GT. Vaccine delivery: a matter of size, geometry, kinetics and molecular patterns. Nat Rev Immunol (2010) 10(11):787-96. doi: $10.1038 /$ nri2868

57. Silva AL, Rosalia RA, Sazak A, Carstens MG, Ossendorp F, Oostendorp J, et al. Optimization of encapsulation of a synthetic long peptide in PLGA nanoparticles: low-burst release is crucial for efficient CD8(+) T cell activation. Eur J Pharm Biopharm (2013) 83(3):338-45. doi:10.1016/j.ejpb.2012.11.006

58. Joshi MD, Unger WJ, Storm G, van Kooyk Y, Mastrobattista E. Targeting tumor antigens to dendritic cells using particulate carriers. J Control Release (2012) 161(1):25-37. doi:10.1016/j.jconrel.2012.05.010
59. Varypataki EM, van der Maaden K, Bouwstra J, Ossendorp F, Jiskoot W. Cationic liposomes loaded with a synthetic long peptide and poly(I:C): a defined adjuvanted vaccine for induction of antigen-specific $\mathrm{T}$ cell cytotoxicity. AAPS J (2015) 17(1):216-26. doi:10.1208/s12248-014-9686-4

60. Watanabe M, Fujihara C, Radtke AJ, Chiang YJ, Bhatia S, Germain RN, et al. Co-stimulatory function in primary germinal center responses: CD40 and B7 are required on distinct antigen-presenting cells. J Exp Med (2017) 214(9):2795-810. doi:10.1084/jem.20161955

61. Brewitz A, Eickhoff S, Dahling S, Quast T, Bedoui S, Kroczek RA, et al. CD8(+) T cells orchestrate pDC-XCR1(+) dendritic cell spatial and functional cooperativity to optimize priming. Immunity (2017) 46(2):205-19. doi:10.1016/j.immuni.2017.01.003

62. Gerner MY, Casey KA, Kastenmuller W, Germain RN. Dendritic cell and antigen dispersal landscapes regulate $\mathrm{T}$ cell immunity. J Exp Med (2017) 214(10):3105-22. doi:10.1084/jem.20170335

63. Gerner MY, Torabi-Parizi P, Germain RN. Strategically localized dendritic cells promote rapid $\mathrm{T}$ cell responses to lymph-borne particulate antigens. Immunity (2015) 42(1):172-85. doi:10.1016/j.immuni.2014.12.024

64. Spranger S, Dai D, Horton B, Gajewski TF. Tumor-residing Batf3 dendritic cells are required for effector $\mathrm{T}$ cell trafficking and adoptive $\mathrm{T}$ cell therapy. Cancer Cell (2017) 31(5):711-23.e4. doi:10.1016/j.ccell.2017. 04.003

65. Salmon H, Idoyaga J, Rahman A, Leboeuf M, Remark R, Jordan S, et al. Expansion and activation of $\mathrm{CD} 103(+)$ dendritic cell progenitors at the tumor site enhances tumor responses to therapeutic PD-L1 and BRAF inhibition. Immunity (2016) 44(4):924-38. doi:10.1016/j.immuni.2016. 03.012

66. Roberts EW, Broz ML, Binnewies M, Headley MB, Nelson AE, Wolf DM, et al. Critical role for CD103(+)/CD141(+) dendritic cells bearing CCR7 for tumor antigen trafficking and priming of $\mathrm{T}$ cell immunity in melanoma. Cancer Cell (2016) 30(2):324-36. doi:10.1016/j.ccell.2016.06.003

67. Merad M, Sathe P, Helft J, Miller J, Mortha A. The dendritic cell lineage: ontogeny and function of dendritic cells and their subsets in the steady state and the inflamed setting. Annu Rev Immunol (2013) 31:563-604. doi:10.1146/ annurev-immunol-020711-074950

68. Cohn L, Delamarre L. Dendritic cell-targeted vaccines. Front Immunol (2014) 5:255. doi:10.3389/fimmu.2014.00255

69. Meixlsperger S, Leung CS, Ramer PC, Pack M, Vanoaica LD, Breton G, et al. CD141+ dendritic cells produce prominent amounts of IFN-alpha after dsRNA recognition and can be targeted via DEC-205 in humanized mice. Blood (2013) 121(25):5034-44. doi:10.1182/blood-2012-12-473413

70. Haniffa M, Shin A, Bigley V, McGovern N, Teo P, See P, et al. Human tissues contain CD141hi cross-presenting dendritic cells with functional homology to mouse CD103+ nonlymphoid dendritic cells. Immunity (2012) 37(1):60-73. doi:10.1016/j.immuni.2012.04.012

71. van der Sluis TC, Sluijter M, van Duikeren S, West BL, Melief CJ, Arens R, et al. Therapeutic peptide vaccine-induced CD8 T cells strongly modulate intratumoral macrophages required for tumor regression. Cancer Immunol Res (2015) 3(9):1042-51. doi:10.1158/2326-6066.CIR-15-0052

72. van der Sluis TC, van Duikeren S, Huppelschoten S, Jordanova ES, Beyranvand Nejad E, Sloots A, et al. Vaccine-induced tumor necrosis factor-producing $\mathrm{T}$ cells synergize with cisplatin to promote tumor cell death. Clin Cancer Res (2015) 21(4):781-94. doi:10.1158/1078-0432.CCR-14-2142

73. Kleinovink JW, Marijt KA, Schoonderwoerd MJA, van Hall T, Ossendorp F, Fransen MF. PD-L1 expression on malignant cells is no prerequisite for checkpoint therapy. Oncoimmunology (2017) 6(4):e1294299. doi:10.1080/ 2162402X.2017.1294299

74. Juneja VR, McGuire KA, Manguso RT, LaFleur MW, Collins N, Haining WN, et al. PD-L1 on tumor cells is sufficient for immune evasion in immunogenic tumors and inhibits CD8 T cell cytotoxicity. J Exp Med (2017) 214(4): 895-904. doi:10.1084/jem.20160801

75. Ahrends T, Babala N, Xiao Y, Yagita H, van Eenennaam H, Borst J. CD27 agonism plus PD-1 blockade recapitulates CD4+ T-cell help in therapeutic anticancer vaccination. Cancer Res (2016) 76(10):2921-31. doi:10.1158/00085472.CAN-15-3130

76. Pitt JM, Vetizou M, Daillere R, Roberti MP, Yamazaki T, Routy B, et al. Resistance mechanisms to immune-checkpoint blockade in cancer: tumorintrinsic and -extrinsic factors. Immunity (2016) 44(6):1255-69. doi:10.1016/ j.immuni.2016.06.001 
77. Robert C, Long GV, Brady B, Dutriaux C, Maio M, Mortier L, et al. Nivolumab in previously untreated melanoma without BRAF mutation. $N$ Engl J Med (2015) 372(4):320-30. doi:10.1056/NEJMoa1412082

78. Tumeh PC, Harview CL, Yearley JH, Shintaku IP, Taylor EJM, Robert L, et al. PD-1 blockade induces responses by inhibiting adaptive immune resistance. Nature (2014) 515(7528):568-71. doi:10.1038/nature13954

79. Unger WW, van Kooyk Y. 'Dressed for success' C-type lectin receptors for the delivery of glyco-vaccines to dendritic cells. Curr Opin Immunol (2011) 23(1):131-7. doi:10.1016/j.coi.2010.11.011

80. Fehres CM, Garcia-Vallejo JJ, Unger WW, van Kooyk Y. Skin-resident antigen-presenting cells: instruction manual for vaccine development. Front Immunol (2013) 4:157. doi:10.3389/fimmu.2013.00157

81. Alloatti A, Kotsias F, Magalhaes JG, Amigorena S. Dendritic cell maturation and cross-presentation: timing matters! Immunol Rev (2016) 272(1):97-108. doi:10.1111/imr.12432

82. Alloatti A, Kotsias F, Pauwels AM, Carpier JM, Jouve M, Timmerman E, et al. Toll-like receptor 4 engagement on dendritic cells restrains phagolysosome fusion and promotes cross-presentation of antigens. Immunity (2015) 43(6):1087-100. doi:10.1016/j.immuni.2015.11.006

83. Samie M, Cresswell P. The transcription factor TFEB acts as a molecular switch that regulates exogenous antigen-presentation pathways. Nat Immunol (2015) 16(7):729-36. doi:10.1038/ni.3196

84. van Montfoort N, Camps MG, Khan S, Filippov DV, Weterings JJ, Griffith JM, et al. Antigen storage compartments in mature dendritic cells facilitate prolonged cytotoxic T lymphocyte cross-priming capacity. Proc Natl Acad Sci U S A (2009) 106(16):6730-5. doi:10.1073/pnas.0900969106

85. Zom GG, Khan S, Filippov DV, Ossendorp F. TLR ligand-peptide conjugate vaccines: toward clinical application. Adv Immunol (2012) 114:177-201. doi:10.1016/B978-0-12-396548-6.00007-X

86. Hajishengallis G, Lambris JD. Microbial manipulation of receptor crosstalk in innate immunity. Nat Rev Immunol (2011) 11(3):187-200. doi:10.1038/nri2918

87. Gringhuis SI, den Dunnen J, Litjens M, van der Vlist M, Geijtenbeek TB. Carbohydrate-specific signaling through the DC-SIGN signalosome tailors immunity to Mycobacterium tuberculosis, HIV-1 and Helicobacter pylori. Nat Immunol (2009) 10(10):1081-8. doi:10.1038/ni.1778

88. Ackerman AL, Giodini A, Cresswell P. A role for the endoplasmic reticulum protein retrotranslocation machinery during crosspresentation by dendritic cells. Immunity (2006) 25(4):607-17. doi:10.1016/j.immuni.2006.08.017

89. Grotzke JE, Kozik P, Morel JD, Impens F, Pietrosemoli N, Cresswell P, et al. Sec61 blockade by mycolactone inhibits antigen cross-presentation independently of endosome-to-cytosol export. Proc Natl Acad Sci U S A (2017) 114(29):E5910-9. doi:10.1073/pnas.1705242114

90. West MA, Lucocq JM, Watts C. Antigen processing and class II MHC peptide-loading compartments in human B-lymphoblastoid cells. Nature (1994) 369(6476):147-51. doi:10.1038/369147a0

91. Groll M, Bajorek M, Kohler A, Moroder L, Rubin DM, Huber R, et al. A gated channel into the proteasome core particle. Nat Struct Biol (2000) 7(11):1062-7. doi:10.1038/80992

92. Blees A, Januliene D, Hofmann T, Koller N, Schmidt C, Trowitzsch S, et al. Structure of the human MHC-I peptide-loading complex. Nature (2017) 551(7681):525-8. doi:10.1038/nature24627
93. Porgador A, Yewdell JW, Deng Y, Bennink JR, Germain RN. Localization, quantitation, and in situ detection of specific peptide-MHC class I complexes using a monoclonal antibody. Immunity (1997) 6(6):715-26. doi:10.1016/ S1074-7613(00)80447-1

94. Sletten EM, Bertozzi CR. Bioorthogonal chemistry: fishing for selectivity in a sea of functionality. Angew Chem Int Ed Engl (2009) 48(38):6974-98. doi:10.1002/anie.200900942

95. Kiick KL, Saxon E, Tirrell DA, Bertozzi CR. Incorporation of azides into recombinant proteins for chemoselective modification by the Staudinger ligation. Proc Natl Acad Sci U S A (2002) 99(1):19-24. doi:10.1073/pnas. 012583299

96. Van Kasteren SI, Kramer HB, Gamblin DP, Davis BG. Site-selective glycosylation of proteins: creating synthetic glycoproteins. Nat Protoc (2007) 2(12):3185-94. doi:10.1038/nprot.2007.430

97. van Kasteren SI, Kramer HB, Jensen HH, Campbell SJ, Kirkpatrick J, Oldham NJ, et al. Expanding the diversity of chemical protein modification allows post-translational mimicry. Nature (2007) 446(7139):1105-9. doi:10.1038/nature05757

98. Kiick KL, Tirrell DA. Protein engineering by in vivo incorporation of nonnatural amino acids: control of incorporation of methionine analogues by methionyl-tRNA synthetase. Tetrahedron (2000) 56(48):9487-93. doi:10.1016/ S0040-4020(00)00833-4

99. Van Hest JCM, Kiick KL, Tirrell DA. Efficient incorporation of unsaturated methionine analogues into proteins in vivo. J Am Chem Soc (2000) 122(7):1282-8. doi:10.1021/ja992749j

100. Pawlak JB, Hos BJ, van de Graaff MJ, Megantari OA, Meeuwenoord N, Overkleeft HS, et al. The optimization of bioorthogonal epitope ligation within MHC-I complexes. ACS Chem Biol (2016) 11(11):3172-8. doi:10.1021/ acschembio.6b00498

101. Pawlak JB, Gential GP, Ruckwardt TJ, Bremmers JS, Meeuwenoord NJ, Ossendorp FA, et al. Bioorthogonal deprotection on the dendritic cell surface for chemical control of antigen cross-presentation. Angew Chem Int Ed Engl (2015) 54(19):5628-31. doi:10.1002/anie.201500301

102. Prescher JA, Dube DH, Bertozzi CR. Chemical remodelling of cell surfaces in living animals. Nature (2004) 430(7002):873-7. doi:10.1038/nature02791

103. van Elsland DM, Bos E, de Boer W, Overkleeft HS, Koster AJ, van Kasteren SI. Detection of bioorthogonal groups by correlative light and electron microscopy allows imaging of degraded bacteria in phagocytes. Chem Sci (2016) 7(1):752-8. doi:10.1039/c5sc02905h

Conflict of Interest Statement: The authors declare that the research was conducted in the absence of any commercial or financial relationships that could be construed as a potential conflict of interest.

Copyright (C) 2018 Hos, Tondini, van Kasteren and Ossendorp. This is an open-access article distributed under the terms of the Creative Commons Attribution License (CC BY). The use, distribution or reproduction in other forums is permitted, provided the original author(s) and the copyright owner are credited and that the original publication in this journal is cited, in accordance with accepted academic practice. No use, distribution or reproduction is permitted which does not comply with these terms. 